\title{
Evaluation of Sex Differences in Murine Diabetic Ketoacidosis and Neutropenic Models of Invasive Mucormycosis
}

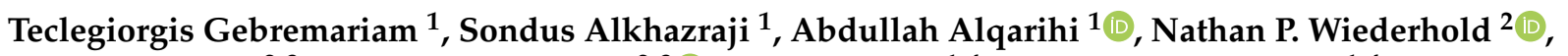 \\ Laura K. Najvar ${ }^{2,3}$, Thomas F. Patterson ${ }^{2,3}{ }^{\circ}$, Scott G. Filler ${ }^{1,4}$ and Ashraf S. Ibrahim ${ }^{1,4, *}$ \\ 1 The Division of Infectious Diseases, The Lundquist Institute for Biomedical Innovation at Harbor-University \\ of California at Los Angeles (UCLA) Medical Center, Torrance, CA 90502, USA; \\ tghbremariam@lundquist.org (T.G.); salkhazraji@lundquist.org (S.A.); aalqarihi@lundquist.org (A.A.); \\ sfiller@lundquist.org (S.G.F.) \\ 2 University of Texas Health Science Center at San Antonio, San Antonio, TX 78229, USA; \\ wiederholdn@uthscsa.edu (N.P.W.); NAJVAR@uthscsa.edu (L.K.N.); patterson@uthscsa.edu (T.F.P.) \\ 3 South Texas Veterans Health Care System, San Antonio, TX 78229, USA \\ 4 David Geffen School of Medicine at UCLA, Los Angeles, CA 90095, USA \\ * Correspondence: ibrahim@lundquist.org; Tel.: +1-310-222-6424
}

check for updates

Citation: Gebremariam, T.; Alkhazraji, S.; Alqarihi, A.; Wiederhold, N.P.; Najvar, L.K.; Patterson, T.F.; Filler, S.G.; Ibrahim, A.S. Evaluation of Sex Differences in Murine Diabetic Ketoacidosis and Neutropenic Models of Invasive Mucormycosis. J. Fungi 2021, 7, 313. https://doi.org/10.3390/jof7040313

Academic Editor: Michaela Lackner

Received: 8 April 2021

Accepted: 16 April 2021

Published: 18 April 2021

Publisher's Note: MDPI stays neutral with regard to jurisdictional claims in published maps and institutional affiliations.

Copyright: (c) 2021 by the authors. Licensee MDPI, Basel, Switzerland. This article is an open access article distributed under the terms and conditions of the Creative Commons Attribution (CC BY) license (https:/ / creativecommons.org/licenses/by/ $4.0 /)$.

\begin{abstract}
There is increased concern that the quality, generalizability and reproducibility of biomedical research can be influenced by the sex of animals used. We studied the differences between male and female mice in response to invasive pulmonary mucormycosis including susceptibility to infection, host immune reaction and responses to antifungal therapy. We used diabetic ketoacidotic (DKA) or neutropenic mice infected with either Rhizopus delemar or Mucor circinelloides. The only difference detected was that when DKA mice were infected with $M$. circinelloides, female mice were more resistant to infection than male mice (median survival time of $5 \mathrm{vs}$. 2 days for female and male mice, respectively). However, a 100\% lethality was detected among infected animals of both sexes. Treatment with either liposomal amphotericin B (L-AMB) or posaconazole (POSA) protected mice from infection and eliminated the difference seen between infected but untreated female and male mice. Treatment with L-AMB consistently outperformed POSA in prolonging survival and reducing tissue fungal burden of DKA and neutropenic mice infected with $R$. delemar or M. circinelloides, in both mouse sexes. While little difference was detected in cytokine levels among both sexes, mucormycosis infection in the DKA mouse model induced more inflammatory cytokines/chemokines involved in neutrophil (CXCL1) and macrophage (CXCL2) recruitment vs. uninfected mice. As expected, this inflammatory response was reduced in the neutropenic mouse model. Our studies show that there are few differences between female and male DKA or neutropenic mice infected with mucormycosis with no effect on the outcome of treatment or host immune response.
\end{abstract}

Keywords: Rhizopus; Mucor; mucormycosis; murine; sex

\section{Introduction}

There is a growing concern in the scientific community and lay public about the reproducibility of biomedical research. Study design elements that are critical to the reproducibility of results include, but are not limited to blinding, randomization and sample-size calculations [1,2]. Pre-clinical research with animal models may be difficult to reproduce, due to differences in the strain of animals that is used, laboratories and laboratory environments and subtle changes in protocols that may not be effectively communicated in publications [1,2]. In addition, there is increased recognition that the quality, generalizability and reproducibility of biomedical research can be influenced by sex of the experimental animal, and that the over-reliance on a single sex of animals in pre-clinical research may obscure key sex differences that could guide clinical trials [1]. Thus, the National Institutes of Health (NIH) now recognizes that the failure to account for 
sex (a biological variable defined by characteristics encoded in DNA, such as reproductive organs and other physiological and functional characteristics) as a key biological variable can undermine the scientific rigor, transparency and generalizability of research findings [3]. Because of this, applications to be considered for funding in fiscal year 2017 and beyond must report plans to balance male and female cells and animals in preclinical studies unless unwarranted based on rigorously defined exceptions, and that the absence of previous data in an area does not by itself constitute a strong justification to use only one sex [3].

Mucormycosis is a life-threatening, fungal infection caused by various species of the order Mucorales. While mucormycosis primarily occurs in patients immunocompromised by diabetic ketoacidosis (DKA), cytotoxic chemotherapy, immunosuppressive therapy and/or hematologic malignancies, immunocompetent patients with severe trauma are also at increased risk of contracting the infection [4-6]. While current treatment options for mucormycosis include the reversal of underlying predisposing factor, surgical debridement of infected foci and antifungal therapy, overall mortality rates remain between 40-90\% [6-8]. Thus, the development of new therapeutic strategies for mucormycosis is of paramount importance. Owing to the rarity of the disease, it is difficult to conduct comparative clinical trials to evaluate treatment options for mucormycosis and there is a heavy reliance on animal models for evaluation and development of novel therapeutic strategies. Two of the murine models that have been developed and made available for the scientific community through the NIH/NIAID pre-clinical resources are models in which DKA is induced in mice or they are rendered neutropenic [9]. These two models represent two patient categories at high risk of mucormycosis [4-6]. We and others have used these models extensively to evaluate the efficacy of current and investigational drugs in treating mucormycosis and to understand the pathogenesis of infection mainly by using male mice [9-15].

Given the lack of knowledge on the effect of mouse sex on mucormycosis, we used the DKA and neutropenic mouse models to investigate differences between males and females in susceptibility to invasive pulmonary mucormycosis, immune responses to infection and antifungal therapy outcome using Rhizopus delemar and Mucor circinelloides, which are two of the most common causes of mucormycosis $[7,16]$.

\section{Materials and Methods}

\subsection{Organisms and Culture Conditions}

Rhizopus arrhizus var. delemar 99-880 and M. circinelloides f. jenssenii DI15-131 are clinical isolates obtained from the Fungus Testing Laboratory at The University of Texas Health Science Center at San Antonio (UTHSCSA). These isolates had been utilized by our laboratory in numerous studies and resulted in consistent infections in animal models $[9,17]$. Both isolates were propagated on potato dextrose agar (PDA) plates for $4-6$ days at $37^{\circ} \mathrm{C}$. Sporangiospores were collected in sterile phosphate buffered saline (PBS) containing $0.01 \%$ Tween 80 , followed by two washes in PBS and the number of spores determined by hemocytometer. The number of sporangiospores per milliliter were adjusted for a working inoculum of $10^{7}$ spores $/ \mathrm{mL}$ of PBS for R. delemar or $10^{8}$ spores $/ \mathrm{mL}$ of PBS for $M$. circinelloides. Sporangiospore viability was determined by quantification of colony-forming units on PDA plates supplemented with $0.1 \%$ Triton X-100.

\subsection{Antifungal Agents}

Posaconazole (POSA) (Merck \& Co., Inc., Rahway, NJ, USA) was purchased as an oral suspension $(200 \mathrm{mg} / 5 \mathrm{~mL}$ ) and kept at room temperature. Liposomal amphotericin B (L-AMB) (Gilead Science, San Dimas, CA, USA) was initially dissolved in irrigation water and diluted into 5\% dextrose water per the manufacturer's instructions. Both drugs were the clinical formulations and were obtained from a local pharmacy. All drugs were prepared fresh dosed per gram mouse body weight. 


\subsection{Mouse Strains and Immunosuppression}

Male or female ICR mice weighing $\sim 25 \mathrm{~g}$ (Envigo, Indianapolis, IN, USA) were used in this study. Mice were housed 5 animals per cage with males and females in separate cages. Mice had access to food and water ad libitum throughout the course of the evaluations. To induce diabetes and slight ketoacidosis, freshly prepared streptozotocin in ice-cold citrate buffer ( $\mathrm{pH} 4.2$ ), was filter sterilized and immediately administered to mice by intraperitoneal injection at $210 \mathrm{mg} / \mathrm{kg}$. Seven days after streptozotocin injection, glycosuria and ketonuria were determined by the use of keto-Diastix reagent strips (Bayer, Elkhart, IN, USA). Cortisone acetate (Sigma-Aldrich, ST. Louis, MO, USA) dissolved in 0.05\% Tween 80 (Sigma-Aldrich) was also administered to mice $(250 \mathrm{mg} / \mathrm{kg})$ subcutaneously on Day -2 and +3 , relative to infection [9].

Neutropenia was induced by administering cyclophosphamide and cortisone acetate. Cyclophosphamide $(25 \mathrm{mg} / \mathrm{mL}$; pharmaceutical grade) was dissolved in irrigation water and administered intraperitoneally at a dose of $200 \mathrm{mg} / \mathrm{kg}$ on days $-2,+3$ and +8 , relative to infection. Cortisone acetate powder was freshly prepared as a suspension of $25 \mathrm{mg} / \mathrm{mL}$ in sterile physiologic phosphate buffered saline and $0.05 \%$ Tween 80 . The suspension was administered subcutaneously at a dose of $500 \mathrm{mg} / \mathrm{kg}$ on days $-2,+3$ and +8 , relative to infection. To prevent bacterial super-infection and deaths in the immunosuppressed mice, mice were given antibacterial prophylaxis consisting of enrofloxacin (enrofloxacin, Bayer, Leverkusen, Germany) at $50 \mathrm{ppm}$ in the mice's drinking water three days prior to infecting with fungal spores, then switched to subcutaneous ceftazidime ( $5 \mathrm{mg} /$ mouse) on day 0 through day +8 for the DKA mice and through day +13 for the neutropenic mice [9].

\subsection{Infection and Treatment}

Mice were infected intratracheally with the appropriate spore inocula. First, mice were sedated by intraperitoneal injection of $0.2 \mathrm{~mL}$ of a mixture of ketamine $82.5 \mathrm{mg} / \mathrm{kg}$ (Phoenix, St. Joseph, MO, USA; prepared from a stock solution of $100 \mathrm{mg} / \mathrm{mL}$ of PBS) and xylazine $6 \mathrm{mg} / \mathrm{Kg}$ (Lloyd Laboratories, Shenandoah, IA, USA; prepared from a stock solution of $100 \mathrm{mg} / \mathrm{mL}$ of PBS) [9]. This dose delivered full anesthesia to the mouse for $\sim 15-30 \mathrm{~min}$. The mice were placed on their backs on heat pads that had been prewarmed to $37^{\circ} \mathrm{C}$ and under heating lamps (at arm's length) to prevent hypothermia. While pulling the tongue anteriorly and to the side with forceps, $25 \mu \mathrm{L}$ of $2.5 \times 10^{5}$ spores of $R$. delemar or $2.5 \times 10^{6}$ spores of $M$. circinelloides was injected through the vocal cords into the trachea with a Fisher brand Gel-loading tip (Cat \# 02-707-138) [9]. The mice were next placed on their backs on the heat pads until they recovered from the anesthesia. To determine the delivered fungal inoculum to the lungs, immediately after infection and prior to recovering from anesthesia, 5 mice per sex were randomly sacrificed, their lungs harvested, homogenized and quantitatively cultured on PDA plates containing $0.1 \%$ Triton X-100 and allowed to incubate at $37^{\circ} \mathrm{C}$ for $48 \mathrm{~h}$.

Following infection, mice were randomly distributed into treatment groups. Uninfected mice that intratracheally received $25 \mu \mathrm{L}$ of PBS alone. Mice were treated with either $15 \mathrm{mg} / \mathrm{kg}$ L-AMB (once daily [qd], administered through the tail vein) or $30 \mathrm{mg} / \mathrm{kg}$ POSA (twice daily [bid], given by oral gavage). Treatment was started $24 \mathrm{~h}$ post infection and continued for 4 days for L-AMB and 7 days for POSA. Infected untreated mice (placebo) received $5 \%$ dextrose water. The primary endpoint for efficacy was time to morbidity of infected mice through day 21 with moribund mice humanely euthanized. Secondary endpoints included assessment of fungal burden in lungs and tissues (primary and secondary target organs [9]) using conidial equivalents (CE)/g of tissue by quantitative PCR (qPCR) [18], and cytokine analysis of lungs homogenates or whole blood sera using a mouse magnetic Luminex assay from R\&D systems (Cat \# LXSAMSM-11) and conducted on mice sacrificed 4 days post infection. The cytokines that were measured were involved in regulating the innate immune response, and many had been reported to influence the host defense against infection caused by Mucorales [19-21]. These included: CCL2/MCP$1 /$ JE, CCL3/MIP- $1 \alpha$, CCL4/MIP-1 $\beta$, CXCL1/KC, IFN- $\gamma$, IL-1 $\alpha$, IL-1 $\beta$, IL-17A, IL-23 p19, 
TNF- $\alpha$ and VEGF. The tissue fungal burden and cytokine analysis were conducted on the same mice to better correlate clearance mechanisms with the inflammatory immune response. All experiments were conducted in duplicate with at least 10 mice per group in each experiment with the exception of uninfected controls which had 3-5 mice per group per experiment.

\section{Results}

\subsection{DKA Mice Infected with R. delemar}

In two independent experiments with similar results, we did not detect any significant difference in survival of male or female DKA mice infected with $R$. delemar 99-880 (5 and 6 days median survival time and $5 \%$ and $0 \%$ overall survival for female and male mice, respectively $[p=1.0]$ ). Consistent with our previous published data in which we used male DKA mice [9], POSA and L-AMB enhanced median survival time and prolonged overall survival with L-AMB outperforming POSA. Specifically, POSA resulted in 10 day median survival time for both female and male mice, while L-AMB resulted in 18 days and $>21$ days median survival time for female and male mice, respectively. Further, POSA and L-AMB treatment caused $\sim 30 \%$ and $\sim 50 \%$ overall survival (Figure $1 \mathrm{~A}$ ). Importantly, both POSA and L-AMB showed similar efficacy in both female and male DKA mice $(p=0.571$ and $p=0.431$ for POSA and L-AMB treatment, respectively) (Figure 1A). Therefore, the mouse sex had no significant effect on outcome of $R$. delemar infection or treatment in this DKA model.
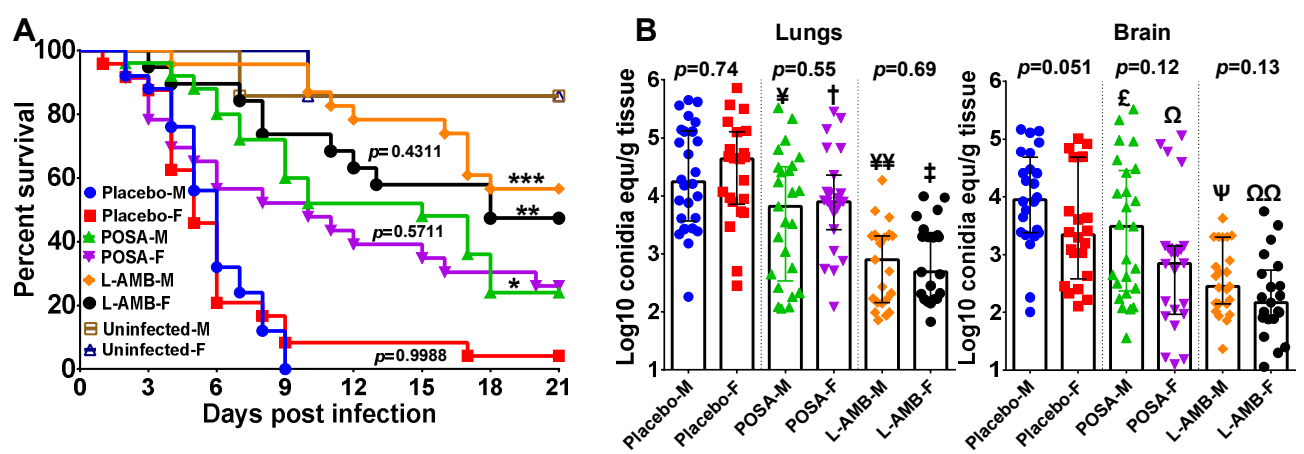

Figure 1. Female and male DKA mice are equally susceptible to $R$. delemar infection. (A) Survival of female (F) or male (M) DKA mice combined from two independent experiments infected with $R$. delemar 99-880. Mice ( $n=21$ to 25 per group, except the uninfected control which had 7 for each sex) were made diabetic and infected. ${ }^{*} p=0.0003$ for POSA-M vs. Placebo-M. ${ }^{* *} p=0.0008$ for L-AMB-F vs. Placebo-F. ${ }^{* * *} p<0.05$ for L-AMB-M vs. Placebo-M or POSA-M. $p$ values on the figure compare female and male mice within the same treatment. (B) Combined tissue fungal burden (qPCR) in lung and brain of mice infected with $R$. delemar. Mice ( $n=20$ per group from 2 experiments) were infected, treated and organs harvested at Day 4 post infection. Lung CFU: ${ }^{¥} p=0.03$ for Placebo-M vs. POSA-M, ${ }^{\dagger} p=0.08$ for Placebo-F vs. POSA-F, ${ }^{¥} p<0.006$ for L-AMB-M vs. Placebo-M or POSA-M, $\ddagger p<0.0001$ for L-AMB-F vs. Placebo-F or POSA-F. Brain CFU: ${ }^{£} p=0.135$ for POSA-M vs. Placebo-M, $\Omega p=0.02$ for POSA-F vs. Placebo-F, ${ }^{\Psi} p=0.01$ for L-AMB-M vs. Placebo-M or POSA-M, ${ }^{\Omega} \Omega p<0.0001$ for L-AMB-F vs. Placebo-F and $p=0.1$ for L-AMB-F vs. POSA-F.

We also analyzed tissue fungal burden of target organs in two independent experiments. The combined data for the lung and brain fungal burden are presented in Figure 1B. The pulmonary fungal burdens of the placebo-treated female and male mice were similar. While there was a trend towards reduced fungal burden in the brains of the control female mice relative to the male mice, this difference did not achieve statistical significance. Consistent with the survival data, both antifungal drugs reduced fungal burden in the lung when compared to placebo-treated mice, with L-AMB outperforming POSA $(>1.0$ log-fold and $0.5 \log$ reduction in L-AMB- $(p<0.0001)$ and POSA-treated mice $(p<0.05$ for male mice and $p<0.08$ for female mice), respectively) (Figure 1B). While L-AMB also 
reduced the brain fungal burden by $>1.0$ log-fold $(p<0.0001)$ in both sexes, POSA caused minimal reduction of $\sim 0.4 \log$-fold in female mice $(p<0.03)$ but not male mice $(p=0.14)$ when compared to their respective placebo groups.

For immunological responses, due to the immunosuppression status of the mice, cytokine analysis of whole serum was not measurable with the overwhelming samples registering values below the limit of detection (LOD ranged from $0.45-134 \mathrm{pg} / \mathrm{mL}$ based on the cytokine being measured). However, cytokine analysis of lung homogenates showed measurable levels of TNF- $\alpha$, IL-23p19, IL-17A, IL-12p70, IL-6, IL-10, IL-1B, IL-1 $\alpha$, IFN- $\gamma$, GM-CSF, CXL1, CXCL-2, CXCL10/CRG-2, CCL2, CCL3, CCL4 and CCL5 (Figure S1). In general, there were no remarkable differences in cytokine levels between female and male mice infected/untreated or those treated with L-AMB or POSA. However, there was a 4 -fold increase in interferon- $\gamma$ among POSA-treated female mice vs. POSA-treated male mice $(p=0.01)$ and a very small drop of $\sim 25 \%$ in the levels of IL-12p70 among female placebo mice vs. male mice $(p=0.02)$.

\subsection{DKA Mice Infected with $M$. circinelloides}

In two independent experiments with similar results, female DKA mice were more resistant to $M$. circinelloides infection when compared to male DKA mice (median survival time of 6 days vs. 3 days and a 100\% mortality on day 12 vs. day 9 for female and male mice, respectively, $p<0.0001$ ) (Figure 2A). Similar to what we found in DKA mice infected with $R$. delemar, both L-AMB and POSA prolonged overall survival of mice infected with M. circinelloides, with L-AMB outperforming POSA. Specifically, L-AMB-treated mice had an overall survival of $\sim 80 \%$ vs. $\sim 40 \%$ of POSA-treated mice ( $p<0.02$ of L-AMB-treated vs. POSA-treated and regardless of the mouse sex). Unlike placebo-treated mice, no differences were seen in the survival of female and male DKA mice when treated with either L-AMB or POSA ( $p=0.695$ for L-AMB-treated female vs. male mice, and $p=0.392$ for POSA-treated female vs. male mice) (Figure 2A).
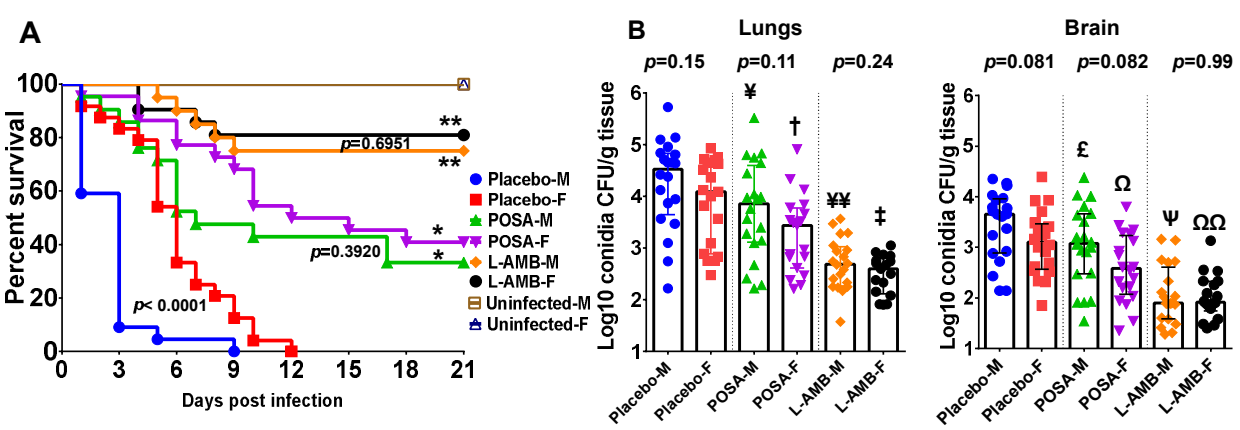

Figure 2. Female DKA mice are slightly more resistant to $M$. circinelloides infection than male DKA mice. (A) Survival of female (F) or male (M) DKA mice combined from two independent experiments infected with M. circinelloides f. jenssenii DI15-131. Mice ( $n=22-24$ per group, except the uninfected control which had 10 for each sex) were made diabetic and infected. ${ }^{*} p<0.03$ for POSA-F or POSA-M vs. Placebo of the corresponding sex. ${ }^{* *} p<0.02$ for L-AMB-F or L-AMB-M vs. Placebo or POSA of the corresponding sex. $p$ values on the figure compare female and male mice within the same treatment. (B) Combined tissue fungal burden (qPCR) in lung and brain of mice infected with $M$. circinelloides. Mice ( $n=20$ per group from 2 experiments) were infected, treated and organs harvested at Day 4 post infection. Lung CFU: $¥ p=0.08$ for POSA-M vs. Placebo-M, $+p=0.02$ for POSA-F vs. Placebo-F, $¥ ¥ p 0.0003$ for L-AMB-M vs. Placebo-M or POSA-M, $\ddagger p<0.001$ for L-AMB-F vs. Placebo-F or POSA-F. Brain CFU: ${ }^{£} p=0.1$ for POSA-M vs. Placebo-M, $\Omega p=0.02$ for POSA-F vs. Placebo-F, $\Psi p<0.0001$ for L-AMB-M vs. Placebo-M or POSA-M, $\Omega \Omega p<0.005$ for L-AMB-F vs. Placebo-F or POSA-F.

The tissue fungal burden experiments showed that sex had no detectable effect on the lung and brain fungal burden in mice infected with M. circinelloides (Figure 2B). Addi- 
tionally, in two independent experiments with DKA mice infected with M. circinelloides, both POSA and L-AMB reduced lung and brain fungal burden vs. placebo treated mice regardless of the mouse sex. Specifically, POSA-treated female mice had $\sim 0.5-\log$ reduction in lung and brain fungal burden vs. placebo $(p=0.02)$, a trend in reduced fungal burden was observed with POSA-treated male mice vs. placebo but that reduction did not reach statistical significance $(p \leq 0.09)$ (Figure 2B). Concordant with the survival studies, L-AMB outperformed POSA in these studies. L-AMB-treated female or male DKA mice had $~ 1.0$ to $2.0-\log$ reduction in lung and brain fungal burden vs. placebo $(p<0.001)$ (Figure $2 \mathrm{~B}$ ). However, unlike the difference seen in survival between placebo female and placebo male mice, no major differences in tissue fungal burden among the organs tested were noticed between the two sexes and regardless of the treatment applied $(p>0.05$ between female and male mice) (Figure 2B).

To analyze the effects of sex on the immunological response to infection, we first attempted to use Luminex technology to measure the levels of cytokine analysis of whole serum. However, all serum cytokine levels were below the limits of detection. Next, we measured the cytokine levels in lung homogenates and detected measurable levels of TNF- $\alpha$, IL-23p19, IL-17A, IL-12p70, IL-6, IL-10, IL-1B, IL-1 $\alpha$, IFN- $\gamma$, GM-CSF, CXL1, CXCL-2, CXCL10/CRG-2, CCL2, CCL3, CCL4 and CCL5. Infection of female mice with M. circinelloides but not males resulted in increased levels of CCL2, CCL3 and CCL4 (Figure S2). These chemokines are mainly associated with recruitment of phagocytes $[22,23]$ and might explain the relative resistance of female mice to mucormycosis when compared to male mice. Notably, infection of both male or female mice with $M$. circinelloides resulted in reduced levels of CCL5, a chemokine usually associated with recruitment with T-cells, eosinophils and basophils [24-26]. None of the other tested cytokines showed any enhanced levels over uninfected mice.

\subsection{Neutropenic Mice Infected with M. circinelloides}

Because a slight difference was observed in female and male DKA mice infected with M. circinelloides, we investigated if sex differences in susceptibility to mucormycosis were also present in the neutropenic mouse model infected with this fungus. We conducted two independent experiments and present the combined data because the results of each experiment were similar. Unlike the results obtained with the DKA mouse model, we did not observe any significant differences in the survival of female or male neutropenic mice infected with M. circinelloides and treated with placebo, L-AMB or POSA (Figure 3A). Consistent with our previously reported data using this model [9], both antifungal agents demonstrated enhanced overall survival vs. placebo regardless of mouse gender $(60 \%-$ $80 \%$ survival for L-AMB-treated or $30 \%-40 \%$ survival for POSA-treated vs. $0 \%$ survival for placebo; $p<0.002$ for either drug vs. placebo) (Figure 3A). Furthermore, L-AMB consistently resulted in 1.5-2.0-log reduction of lung and brain fungal burden in both female and male mice vs. placebo $(p<0.0001)$. POSA also reduced fungal burden $(\sim 1.0-\log )$ in lung, but not the brain, of infected mice when compared to placebo $(p<0.01)$, but in general this effect was inferior to LAMB (Figure 3B). These results confirm the reported superiority of L-AMB over POSA in treating mucormycosis. Importantly, and consistent with the survival studies, no gender differences were noticed in these studies.

Cytokine analysis of lung homogenates, but not sera, showed measurable levels of TNF- $\alpha$, IL-23p19, IL-17 $\alpha$, IL-1 $\beta$, IL-1 $\alpha$, IFN- $\gamma$, CXCL1, CCL2, CCL3, CCL4 and VEGF. Subtly elevated levels of CCL2 were detected in placebo-male compared to placebo-female mice. Consistently lower levels of inflammatory cytokines including IL-17 $\alpha$, IFN- $\gamma$ and IL-1 $\alpha$ were detected in POSA-treated female mice vs. POSA-treated male (Figure S3). However, these differences in cytokines levels are not of large magnitude and they appear to have little effect, if any, on the course of infection as evident by the similar survival and tissue fungal burden among female and male neutropenic mice. 

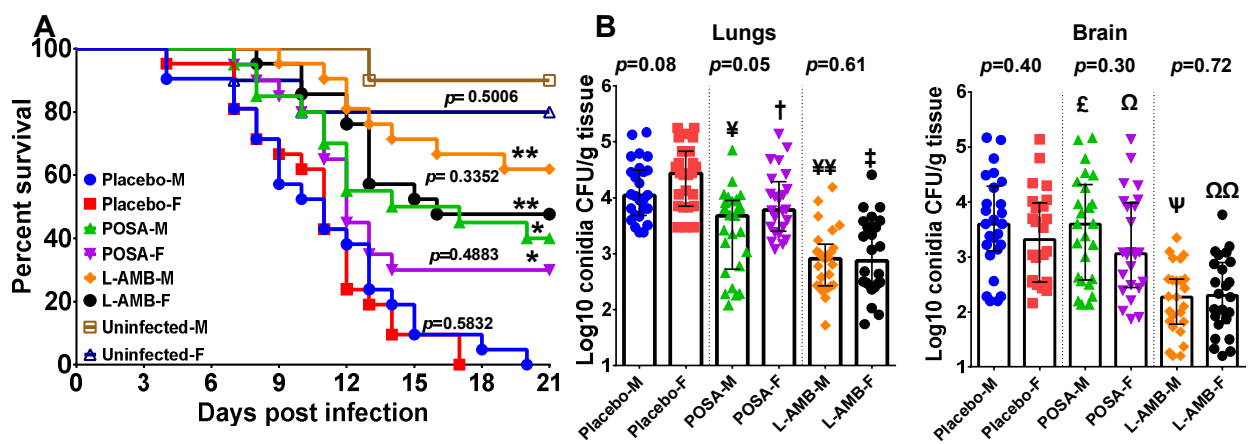

Figure 3. Female and male neutropenic mice are equally susceptible to $M$. circinelloides infection. (A) Survival of female (F) or male (M) neutropenic mice combined from two independent experiments infected with $M$. circinelloides f. jenssenii DI15-131. Mice $(n=21$ per group, except the uninfected control which had 10 for each sex) were made neutropenic and infected. ${ }^{*} p=0.002$ for POSA F or POSA M vs. Placebo of the corresponding sex. ${ }^{* *} p<0.001$ for L-AMB-F or L-AMB-M vs. Placebo of the corresponding sex. $p$ values on the figure compare female and male mice within the same treatment. (B) Combined tissue fungal burden (qPCR) in lung and brain of mice infected with $M$. circinelloides. Mice ( $n=26$ in each group from 2 experiments) were infected, treated and organs harvested at Day 4 post infection. Lung CFU: ${ }^{¥} p=0.001$ for POSA-M vs. Placebo-M, ${ }^{\dagger} p=0.005$ for POSA-F vs. Placebo-F, $¥ ¥ p 0.01$ for L-AMB-M vs. Placebo-M or POSA-M, $\ddagger p<0.0001$ for L-AMB-F vs. Placebo-F or POSA-F. Brain CFU: ${ }^{£} p=0.75$ for POSA-M vs. Placebo-M, ${ }^{\Omega} p=0.53$ for POSA-F vs. Placebo-F, ${ }^{\Psi} p<0.0001$ for L-AMB-M vs. Placebo-M or POSA-M, ${ }^{\Omega} p<0.005$ for L-AMB-F vs. Placebo-F or POSA-F.

\section{Discussion}

In medical mycology, few sex-related differences have been reported. One example where differences clearly exist between males and females is in infections caused by Paracoccidioides species, which are endemic in certain areas of South America [27-29]. The severity of incidence and severity of disease caused by this fungal species are both greater in males than in females, both in patients and experimentally infected animals [27-30]. Studies have demonstrated that this difference between the sexes is related to both the endocrine and immune responses. Estrogen has a direct effect on the growth of the fungus, as well as inhibiting the conversion to the yeast morphology. The immune response is also considered to be sexually dimorphic, as female develop more effective humoral and cell-mediated pro-inflammatory responses than males [31-34]. For example, in the asymptomatic form of paracoccidioidomycosis, a T-helper type 1 (Th1) response occurs, while a T-helper type 2 (Th2) response has been associated with severe disease. Interestingly, the endocrine and immune responses may be linked, as estrogen has been shown to stimulate proinflammatory cytokines (e.g., IL-12, IFN- $\gamma$ and TNF- $\alpha$ ), and down-regulate IL-10 [30]. In contrast, the synthesis of IL-10 may be enhanced by testosterone.

While the Th1/Th2 paradigm has not been extensively studied in relation to mucormycosis, studies conducted on healthy individuals have shown the presence of specific anti-Rhizopus oryzae ( . arrhizus) T-cells that are characterized as memory Th1 cells that are capable of producing interferon- $\gamma$ and enhance the anti-Mucorales phagocyte activity [35]. This study indicates that similar to the other mold infection, aspergillosis [36-39], a Th1 immune response is likely to be protective against mucormycosis. Therefore, females might be more resistant to mucormycosis than males. This assumption is modestly supported by two studies. The first is a review of 929 reported cases of mucormycosis that have been reported in the English-language literature between 1885 and 2005 which showed that mucormycosis in males represented $65 \%$ of the reported cases vs. $35 \%$ in females [7]. Additionally, a recent study that evaluated the newly approved antifungal agent isavuconazole in treating mucormycosis, showed that $81 \%$ of the enrollee were males, indicating that the disease is potentially more prevalent in males than females [40]. 
We used three models of intratracheal mucomrycosis infection to study the effect of mouse sex on infection and antifungal treatment outcome, and on host immune response. These included DKA mice infected with either $R$. delemar or $M$. circinelloides, and neutropenic mice infected with $M$. circinelloides. These two isolates are among the most commonly isolated Mucorales from patients [41]. The only evidence for an effect of mouse gender on the infection outcome was noticed with DKA female mice being more resistant than male mice when infected with M. circinelloides (Figure 2A). However, this difference in susceptibility to infection was very subtle and did not appear to have an effect on the outcome of antifungal treatment. Additionally, this subtle resistance of female DKA mice to infection was not detected when $R$. delemar was used to infect the DKA mice. Consistent with little effect of mouse sex on the infection/treatment outcome, no differences between female and male mice were noted in neutropenic mice infected with $M$. circinelloides. Furthermore, few differences were detected in cytokine levels among both sexes in the DKA or neutropenic mice. However, it appeared that in the DKA mouse model, the infection induced more inflammatory cytokines and chemokines involved in neutrophil (CXCL1) [23] and macrophage (CXCL2) [42] recruitment vs. uninfected mice and regardless of the mouse gender. As expected, this enhanced inflammatory response was reduced in the neutropenic mouse model. Thus, there is little effect, if any, of mouse gender on the outcome of murine mucormycosis using these two models. Based on these results, it is possible to indifferently use male, female mice or a combination of both for animal models of invasive mucormycosis when using the outbred ICR mice. Outbred mice are preferred to inbred mice in treatment experiments to account for inter-individual variability.

Our studies with the DKA and neutropenic mouse models also confirmed previously reported data of the superiority of L-AMB when compared to POSA treatment [9,43]. These results also reflect the recent Global guidelines of using L-AMB as a first-line therapy and reserving POSA treatment for salvage therapy [6]. It is also reassuring that the female and male mice responded to L-AMB or POSA treatment favorably in both models and with two different agents of mucormycosis.

Supplementary Materials: The following are available online at https:/ /www.mdpi.com/article/10 .3390/jof7040313/s1, Figure S1: Cytokine analysis of lung homogenate from female or male DKA mice infected with R. delemar. Figure S2: Cytokine analysis of lung homogenate from female or male DKA mice infected with M. circinelloides $f$. jenssenii, Figure S3: Cytokine analysis of lung homogenate from female or male neutropenic mice infected with $M$. circinelloides $f$. jenssenii.

Author Contributions: Conceptualization, N.P.W., T.F.P., S.G.F. and A.S.I.; methodology, T.G., S.A., A.A. and A.S.I.; formal analysis, T.G., A.S.I.; data curation, T.G., A.A. and A.S.I.; writing—original draft preparation, T.G. and A.S.I.; writing-review and editing, N.P.W., T.F.P. and S.G.F.; supervision, A.S.I.; project administration, L.K.N. and A.S.I.; funding acquisition, N.P.W., T.F.P., S.G.F. and A.S.I. All authors have read and agreed to the published version of the manuscript.

Funding: This research was funded by Public Health Service contract HHSN272201000038I/Task Order HHSN27200008 and grant R01 AI063503.

Institutional Review Board Statement: Animal studies were approved by the IACUC of the Lundquist Institute at Harbor-UCLA Medical Center, according to the NIH guidelines for animal housing and care.

Informed Consent Statement: Not applicable.

Data Availability Statement: The data presented in this study are available in this article and the supplementary figures. Source data are available from the corresponding author upon request.

Conflicts of Interest: A.S.I. owns shares in Vitalex Biosciences, a start-up company that is developing immunotherapies and diagnostics for mucormycosis. N.P.W. has received funding (to UT Health San Antonio) from Astellas, bioMerieux, Covance, F2G and Sfunga, and has served as a scientific advisor for Mayne Pharma. The remaining authors declare no competing interests. 


\section{References}

1. Clayton, J.A.; Collins, F.S. Policy: NIH to balance sex in cell and animal studies. Nature 2014, 509, 282-283. [CrossRef]

2. Collins, F.S.; Tabak, L.A. Policy: NIH plans to enhance reproducibility. Nature 2014, 505, 612-613. [CrossRef] [PubMed]

3. NIH. Considerations of Sex as a Biological Variable in NIH-Funded Research. 2015. Available online: https:/ / grants.nih.gov / grants/guide/notice-files/not-od-15-102.html (accessed on 1 April 2021).

4. Spellberg, B.; Edwards, J., Jr.; Ibrahim, A. Novel perspectives on mucormycosis: Pathophysiology, presentation, and management. Clin. Microbiol. Rev. 2005, 18, 556-569. [CrossRef] [PubMed]

5. Sugar, A.M. Agents of Mucormycosis and Related Species. In Principles and Practice of Infectious Diseases, 6th ed.; Mandell, G.L., Bennett, J.E., Dolin, R., Eds.; Elsevier: Philadelphia, PA, USA; Churchill Livingstone: London, UK, 2005; pp. $2973-2984$.

6. Cornely, O.A.; Alastruey-Izquierdo, A.; Arenz, D.; Chen, S.C.A.; Dannaoui, E.; Hochhegger, B.; Hoenigl, M.; Jensen, H.E.; Lagrou, K.; Lewis, R.E.; et al. Global guideline for the diagnosis and management of mucormycosis: An initiative of the European Confederation of Medical Mycology in cooperation with the Mycoses Study Group Education and Research Consortium. Lancet Infect. Dis. 2019, 19, e405-e421. [CrossRef]

7. Roden, M.M.; Zaoutis, T.E.; Buchanan, W.L.; Knudsen, T.A.; Sarkisova, T.A.; Schaufele, R.L.; Sein, M.; Sein, T.; Chiou, C.C.; Chu, J.H.; et al. Epidemiology and Outcome of Zygomycosis: A Review of 929 Reported Cases. Clin. Infect. Dis. 2005, 41, 634-653. [CrossRef] [PubMed]

8. Gleissner, B.; Schilling, A.; Anagnostopolous, I.; Siehl, I.; Thiel, E. Improved Outcome of Zygomycosis in Patients with Hematological Diseases? Leuk. Lymphoma 2004, 45, 1351-1360. [CrossRef] [PubMed]

9. Luo, G.; Gebremariam, T.; Lee, H.; French, S.W.; Wiederhold, N.P.; Patterson, T.F.; Filler, S.G.; Ibrahim, A.S. Efficacy of Liposomal Amphotericin B and Posaconazole in Intratracheal Models of Murine Mucormycosis. Antimicrob. Agents Chemother. 2013, 57, 3340-3347. [CrossRef]

10. Gebremariam, T.; Wiederhold, N.P.; Alqarihi, A.; Uppuluri, P.; Azie, N.; Edwards, J.E.; Ibrahim, A.S. Monotherapy or combination therapy of isavuconazole and micafungin for treating murine mucormycosis. J. Antimicrob. Chemother. 2016, 72, 462-466. [CrossRef]

11. Gebremariam, T.; Alkhazraji, S.; Baldin, C.; Kovanda, L.; Wiederhold, N.P.; Ibrahim, A.S. Prophylaxis with Isavuconazole or Posaconazole Protects Immunosuppressed Mice from Pulmonary Mucormycosis. Antimicrob. Agents Chemother. 2017, 61, e02589-16. [CrossRef]

12. Gebremariam, T.; Lin, L.; Liu, M.; Kontoyiannis, D.P.; French, S.; Edwards, J.E., Jr.; Filler, S.G.; Ibrahim, A.S. Bicarbonate Correction of Ketoacidosis Alleviates Mucormycosis Through Host, Pathogen. Interact. J. Clin. Investig. 2016, in press. [CrossRef]

13. López-Fernández, L.; Sanchis, M.; Navarro-Rodríguez, P.; Nicolás, F.E.; Silva-Franco, F.; Guarro, J.; Garre, V.; Navarro-Mendoza, M.I.; Pérez-Arques, C.; Capilla, J. Understanding Mucor circinelloides pathogenesis by comparative genomics and phenotypical studies. Virulence 2018, 9, 707-720. [CrossRef] [PubMed]

14. Sun, Q.N.; Najvar, L.K.; Bocanegra, R.; Loebenberg, D.; Graybill, J.R. In Vivo Activity of Posaconazole against Mucor spp. in an Immunosuppressed-Mouse Model. Antimicrob. Agents Chemother. 2002, 46, 2310-2312. [CrossRef] [PubMed]

15. Rodríguez, M.M.; Serena, C.; Mariné, M.; Pastor, F.J.; Guarro, J. Posaconazole Combined with Amphotericin B, an Effective Therapy for a Murine Disseminated Infection Caused by Rhizopus oryzae. Antimicrob. Agents Chemother. 2008, 52, $3786-3788$. [CrossRef] [PubMed]

16. Skiada, A.; Pagano, L.; Groll, A.; Zimmerli, S.; Dupont, B.; Lagrou, K.; Lass-Florl, C.; Bouza, E.; Klimko, N.; Gaustad, P.; et al. Zygomycosis in Europe: Analysis of 230 cases accrued by the registry of the European Confederation of Medical Mycology (ECMM) Working Group on Zygomycosis between 2005 and 2007. Clin. Microbiol. Infect. 2011, 17, 1859-1867. [CrossRef] [PubMed]

17. Gebremariam, T.; Liu, M.; Luo, G.; Bruno, V.; Phan, Q.T.; Waring, A.J.; Edwards, J.E.; Filler, S.G.; Yeaman, M.R.; Ibrahim, A.S. CotH3 mediates fungal invasion of host cells during mucormycosis. J. Clin. Investig. 2014, 124, 237-250. [CrossRef]

18. Ibrahim, A.S.; Bowman, J.C.; Avanessian, V.; Brown, K.; Spellberg, B.; Edwards, J.E., Jr.; Douglas, C.M. Caspofungin Inhibits Rhizopus oryzae 1,3- $\beta$-d-Glucan Synthase, Lowers Burden in Brain Measured by Quantitative PCR, and Improves Survival at a Low but Not a High Dose during Murine Disseminated Zygomycosis. Antimicrob. Agents Chemother. 2005, 49, 721-727. [CrossRef]

19. Castillo, P.; Wright, K.E.; Kontoyiannis, D.P.; Walsh, T.; Patel, S.; Chorvinsky, E.; Bose, S.; Hazrat, Y.; Omer, B.; Albert, N.; et al. A New Method for Reactivating and Expanding T Cells Specific for Rhizopus oryzae. Mol. Ther. Methods Clin. Dev. 2018, 9, 305-312. [CrossRef]

20. Gil-Lamaignere, C.; Simitsopoulou, M.; Roilides, E.; Maloukou, A.; Winn, R.M.; Walsh, T.J. Interferon- gamma and GranulocyteMacrophage Colony-Stimulating Factor Augment the Activity of Polymorphonuclear Leukocytes against Medically Important Zygomycetes. J. Infect. Dis. 2005, 191, 1180-1187. [CrossRef]

21. Montaño, D.E.; Voigt, K. Host Immune Defense upon Fungal Infections with Mucorales: Pathogen-Immune Cell Interactions as Drivers of Inflammatory Responses. J. Fungi 2020, 6, 173. [CrossRef]

22. Bennouna, S.; Bliss, S.K.; Curiel, T.J.; Denkers, E.Y. Cross-Talk in the Innate Immune System: Neutrophils Instruct Recruitment and Activation of Dendritic Cells during Microbial Infection. J. Immunol. 2003, 171, 6052-6058. [CrossRef]

23. Sawant, K.V.; Poluri, K.M.; Dutta, A.K.; Sepuru, K.M.; Troshkina, A.; Garofalo, R.P.; Rajarathnam, K. Chemokine CXCL1 mediated neutrophil recruitment: Role of glycosaminoglycan interactions. Sci. Rep. 2016, 6, 33123. [CrossRef] 
24. Murooka, T.T.; Rahbar, R.; Platanias, L.C.; Fish, E.N. CCL5-mediated T-cell chemotaxis involves the initiation of mRNA translation through mTOR/4E-BP1. Blood 2008, 111, 4892-4901. [CrossRef] [PubMed]

25. John, A.E.; Berlin, A.A.; Lukacs, N.W. Respiratory syncytial virus-induced CCL5/RANTES contributes to exacerbation of allergic airway inflammation. Eur. J. Immunol. 2003, 33, 1677-1685. [CrossRef] [PubMed]

26. Lapteva, N.; Huang, X.F. CCL5 as an adjuvant for cancer immunotherapy. Expert Opin. Biol. Ther. 2010, 10, 725-733. [CrossRef] [PubMed]

27. Arango, M.; Yarzábal, L. T-cell dysfunction and hyperimmunoglobulinemia E in paracoccidioidomycosis. Mycopathologia 1982, 79, 115-123. [CrossRef] [PubMed]

28. Mota, N.; Rezkallah-Iwasso, M.; Peraçoli, M.; Audi, R.; Mendes, R.; Marcondes, J.; Marques, S.; Dillon, N.; Franco, M. Correlation between cell-mediated immunity and clinical forms of paracoccidioidomycosis. Trans. R. Soc. Trop. Med. Hyg. 1985, 79, 765-772. [CrossRef]

29. Singer-Vermes, L.M.; Caldeira, C.B.; Burger, E.; Calich, V.L.G. Experimental murine paracoccidioidomycosis: Relationship among the dissemination of the infection, humoral and cellular immune responses. Clin. Exp. Immunol. 2008, 94, 75-79. [CrossRef]

30. Pinzan, C.F.; Ruas, L.P.; Casabona-Fortunato, A.S.; Carvalho, F.C.; Roque-Barreira, M.-C. Immunological Basis for the Gender Differences in Murine Paracoccidioides brasiliensis Infection. PLoS ONE 2010, 5, e10757. [CrossRef]

31. Restrepo, A.; Salazar, M.E.; Cano, L.E.; Stover, E.P.; Feldman, D.; Stevens, D.A. Estrogens inhibit mycelium-to-yeast transformation in the fungus Paracoccidioides brasiliensis: Implications for resistance of females to paracoccidioidomycosis. Infect. Immun. 1984, 46, 346-353. [CrossRef]

32. Salazar, M.E.; Restrepo, A.; Stevens, D.A. Inhibition by estrogens of conidium-to-yeast conversion in the fungus Paracoccidioides brasiliensis. Infect. Immun. 1988, 56, 711-713. [CrossRef]

33. Sano, A.; Nishimura, K.; Miyaji, M. Effects of Sex Hormones on Sexual Difference of Experimental Paracoccidioidomycosis. Nippon. Ishinkin Gakkai Zasshi 1999, 40, 1-8. [CrossRef]

34. Muchmore, H.G.; McKown, B.A.; Mohr, J.A. Effects of the steroid hormones on the proliferation of Paracoccidioidomicosis braziliensis. Boletin de la Sanit. Panam. Pan Am. Sanit. Bur. 1974, 77, 55-70.

35. Schmidt, S.; Tramsen, L.; Perkhofer, S.; Lass-Flörl, C.; Röger, F.; Schubert, R.; Lehrnbecher, T. Characterization of the Cellular Immune Responses to Rhizopus oryzae With Potential Impact on Immunotherapeutic Strategies in Hematopoietic Stem Cell Transplantation. J. Infect. Dis. 2012, 206, 135-139. [CrossRef] [PubMed]

36. Herbrecht, R.; Denning, D.W.; Patterson, T.F.; Bennett, J.E.; Greene, R.E.; Oestmann, J.-W.; Kern, W.V.; Marr, K.A.; Ribaud, P.; Lortholary, O.; et al. Voriconazole versus Amphotericin B for Primary Therapy of Invasive Aspergillosis. N. Engl. J. Med. 2002, 347, 408-415. [CrossRef] [PubMed]

37. Maertens, J.A.; Raad, I.I.; Marr, K.A.; Patterson, T.F.; Kontoyiannis, D.P.; Cornely, O.A.; Bow, E.J.; Rahav, G.; Neofytos, D.; Aoun, M.; et al. Isavuconazole versus voriconazole for primary treatment of invasive mould disease caused by Aspergillus and other filamentous fungi (SECURE): A phase 3, randomised-controlled, non-inferiority trial. Lancet 2016, 387, 760-769. [CrossRef]

38. Cornely, O.A.; Maertens, J.; Winston, D.J.; Perfect, J.; Ullmann, A.J.; Walsh, T.J.; Helfgott, D.; Holowiecki, J.; Stockelberg, D.; Goh, Y.-T.; et al. Posaconazole vs. Fluconazole or Itraconazole Prophylaxis in Patients with Neutropenia. N. Engl. J. Med. 2007, 356, 348-359. [CrossRef] [PubMed]

39. Ullmann, A.J.; Lipton, J.H.; Vesole, D.H.; Chandrasekar, P.; Langston, A.; Tarantolo, S.R.; Greinix, H.; De Azevedo, W.M.; Reddy, V.; Boparai, N.; et al. Posaconazole or Fluconazole for Prophylaxis in Severe Graft-versus-Host Disease. N. Engl. J. Med. 2007, 356, 335-347. [CrossRef] [PubMed]

40. Marty, F.M.; Ostrosky-Zeichner, L.; Cornely, O.A.; Mullane, K.M.; Perfect, J.R.; Thompson, G.R.; Alangaden, G.J.; Brown, J.M.; Fredricks, D.N.; Heinz, W.J.; et al. Isavuconazole treatment for mucormycosis: A single-arm open-label trial and case-control analysis. Lancet Infect. Dis. 2016, 16, 828-837. [CrossRef]

41. Skiada, A.; Lass-Floerl, C.; Klimko, N.; Ibrahim, A.; Roilides, E.; Petrikkos, G. Challenges in the diagnosis and treatment of mucormycosis. Med Mycol. 2018, 56, S93-S101. [CrossRef]

42. Xu-Vanpala, S.; Deerhake, M.E.; Wheaton, J.D.; Parker, M.E.; Juvvadi, P.R.; Maciver, N.; Ciofani, M.; Shinohara, M.L. Functional heterogeneity of alveolar macrophage population based on expression of CXCL2. Sci. Immunol. 2020, 5, eaba7350. [CrossRef]

43. Ibrahim, A.S.; Gebremariam, T.; Schwartz, J.A.; Edwards, J.E.; Spellberg, B. Posaconazole Mono- or Combination Therapy for Treatment of Murine Zygomycosis. Antimicrob. Agents Chemother. 2008, 53, 772-775. [CrossRef] 